\title{
INTERACCION DE PERSONAS CON SERES DEL VOLCAN EN: DEGÜNCHE, UN RELATO MAPUCHE
}

\author{
Yosuke Kuramochi \\ Universidad Católica de Temuco \\ Temuco. Chile
}

\begin{abstract}
The author describes the relationships established between the entities and the structures of a narrative of the Mapuche oral tradition. The article includes the Mapuche version followed by a word-by-word translation and a free translation into Spanish.
\end{abstract}

\section{Introducción}

Me parecen previas y necesarias algunas precisiones generales y básicas sobre la llamada conversación o ngïtram. Una forma de comunicación oral de los mapuches que se asimila a la categoría del relato en lo que por esto se entiende en la cultura occidental, y que, en lo principal, siendo una relación de hechos acaecidos al narrador o a alguien que éste o sus antepasados conocieron, tiene el estatus de acontecimiento verdadero, en términos de sucesos acaecidos sea cual sea la naturaleza de éstos; este rasgo lo distingue del epew, el cual, aunque su contenido alegorizado es verdadero, no tiene el carácter de suceso realmente acaecido. El mismo rasgo de verdad como acontecimiento sucedido pero bajo la forma de percepción inesperada de fenómenos con significados descifrables, o de sucesos de una realidad diferente, codificada y predictiva, pero perceptible y debida a causas no naturales, tiene el perimontu, otra forma de aconteceres que son transmitidos bajo las condiciones generales de lo que llamamos 'relato'.

1.1. El Narrador. Se presenta con ciertas características generales de una cierta movilidad o no situacionalidad en relación al tiempo, siendo el yo, en la delimitación de Benveniste (1970), un elemento situacional y ordenador con respecto a un tú, a un antes y a un después; éste se desplaza constantemente en la relación discursiva. A este respecto:

a) La voz narrativa -morfológicamente-se encuentra siempre actualizada en primera persona. El narrador desplaza y entrega la voz para la enunciación a la persona que contó con anterioridad lo que a él le llegó, y si en ese sector del relato aparecen personajes, éstos asumirán la voz de primera persona y en tiempo presente. No hay señalizaciones lingüísticas que permitan distinguir estos relevos y secuencializar estableciendo las distancias temporales.

b) En la situación narrativa normal es necesario un destinatario real de los contenidos que están siendo entregados, porque, desde la sabiduría que está en el flujo de la tradición ha sido tejida, en las hebras de un acontecimiento, la historia que se entregó al que ahora, en situación de comunicar, activa y deriva desde la corriente del conocimiento tradicional bajo la forma de un discurso informativo. Por ello se entrega, por ejemplo, a una sobrina, como es el caso del relato del que vamos a ocuparnos.

c) Además, la temporalidad del relato en cuanto a su ordenación secuencial, se ve afectada por una relatividad distributiva que compromete a los acontecimientos relatados, la cual es producto de la voz narrativa. De este 
modo, un sector del relato puede comprender elementos en forma incompleta o anticipada (para el lector u oyente occidental). Tales elementos, sin embargo, son comprensibles para el destinatario mapuche; constituyen un avance de lo que está sucediendo, lo cual será desarrollado más adelante. En otras palabras, el omnipresente del suceder en el tiempo desde el yo y la situación inmediata, no permiten los distanciamientos y las delimitaciones por formas verbales de tiempo referidas a la voz narrativa en primera persona; esto tal vez se deba a la forma como los sujetos se perciben en relación a la realidad: ellos forman parte de ella, y ésta no se encuentra recortada y diferenciada totalmente del sujeto '.

1.2. Final del relato. El relato es una parte de la corriente fluyente de la tradición. Esta comprende más que un conjunto de relaciones orales guardadas en la memoria, es el conjunto del saber y su relación con el suceder de antes y de ahora. De tal modo, si se narra algo, será un trozo recortado en forma de lenguaje bajo la rección de un contenido transmitido. No obstante, tal contenido guarda nexos con el conjunto de la tradición. Así, una nueva versión puede desarrollar otros aspectos de él, y asimismo, pueden variar las perspectivas de acuerdo con el narrante. Por ello las versiones que se originan de preguntas con respecto a ciertos tópicos de un relato, originan versiones con nuevos contenidos. Dada esta situación, los relatos terminan con un "hasta aquí llega no más mi saber sobre este asunto"; esto no es, ni con mucho, el equivalente a nuestro "fin" que clausura $^{2}$ la historia de un relato como objeto verbal acabado y autónomo. La conversación puede continuar sobre otro aspecto de lo ordenado en la relación entregada, por el narrante o por otra persona.

1.3. Verdad e Historia. En la narración se entrecruzan e interactúan lo que para nosotros son diversos niveles de la realidad (Grebe 1972), ello debido a esta particular percepción del mundo que refleja un lenguaje ajeno a lo histórico en el sentido de pasado irrepetible o acabado. La oralidad tiene esa propiedad ahistórica, y por ello: atemporal, aespacial y ataxonómica. La presencia de otras realidades atemporales, la polarización de lo de antes en el presente, por la vigencia que implica su verdad y por la reedición virtual de lo antes ocurrido ${ }^{3}$, hacen que los relatos sean verdaderos y formas de un conocimiento útil para el mapuche.

\section{El relato 'Gente del volcán'}

Cuando llegó la guerra con los españoles a nuestras tierras, toda la gente huyó dejando abandonado el lugar. Acerca de la historia de este asalto a las tierras de la familia de la que desciende mi suegra, me la dejó ella a través de las conversaciones con las que me instruía, entregándome nuestro pasado.

Aquel hombre y su esposa -la abuela de mi suegra-, tenía cuatro hijos. Por ese tiempo de la huida, dijo el hombre un día:

-Llevaré a mi esposa y a nuestros hijos hasta aquel lugar de las montañas en donde el río es más impetuoso y turbulento. Allí, dejaré a mi mujer-. Así dijo el esposo, y agregó: -Yo voy a irme hacia el lado de Argentina a hacer ganado, cuando vuelva, pasaré a buscarte-. Así le dijo a la que era su esposa. Así, partieron pues con sus hijos. Y entonces pasó a dejarla junto a ese lugar del río que era muy turbulento y se fue.

"El tiempo que él estaría por allá yo no lo sabía- dijo la mujer. -Todo el día me lo pasaba haciendo rogaciones. Todo el día estaba de rodillas, ¡Qué sería de mí, qué habría de pasarme! ¿Qué iba a hacer para salvar la vida de mis hijos! Andaba por esos lugares "el viejo hermano", el león, él podía coger a uno de mis hijos, enfermedades podía acarrearnos a nosotros". Eso decía la abuela de mi suegra.

"Así pues fueron los padecimientos que experimentamos, a causa de esa gente de otra parte que llegó a nuestra tierra- decía mi suegra que decía su abuelita-. Pasa el tiempo, pasan los soles ¿cuánto tiempo habrá pasado ya? ¿cuándo volveré a escuchar otra vez la voz de mi hombre? "Estando en ese lugar, mi hija hablaba con otra persona y esa persona hablaba con ella, sin embargo, yo nunca vi quién era, no sabía cómo era él. Le pregunté sobre esto a la que era mi hija. Ella no me contestó mi pregunta, sólo se sonrió diciendo: $-Y a$ andas hablando tonteras como siempre-. ¿Quién es el que viene a hablar contigo?, le volvía a preguntar. Pero ella se quedó callada. 
"Pasaron muchos días. Después de transcurrido mucho tiempo, se presentó ante mí dejándose ver, el que hablaba con mi hija, y me dijo:

-Yo era el que venía a hablar con tu hija. Así, lo que es tuyo es mío, porque yo te la tengo [Ñienmayaeyu]. "¡Hoy, irás a hablar con tu suegra!" me dijo mi padre, por eso hoy vine a darme a conocer y a conocerte.

"Me alegré de escuchar todo esto. Había pues gente por aquí y era posible que me salvara. El nos dará con qué alimentarnos, nos dijo en su conversación ese día el visitante, antes de irse. Así, al día siguiente vino él, el que sería mi yerno trayendo un animal.

"Por la mañana vi al animal de pie en donde lo vinieron a dejar ¿Quiénes vinieron a dejarlo ahí? Unos momentos más tarde mi yerno apareció tras el animal. Vino a carnear su animal para mí.

Entonces comí carne; ya casi moríamos de inanición yo y mis cuatro hijos. Así, me hizo entrega del caballo, era para mí el animal hecho carne. Bastantes días tuvimos para comer. "Mi suegra decía que eso decía su abuelita del hombre ése. Fijaron entonces un día:

"Dijo el que era mi yerno:

- El día indicado los llevaré a todos ustedes, porque éste va a ser un año muy malo con un muy crudo invierno.

"Llegado el día nos vinieron a buscar. Llegamos allá al volcán. Antes de ingresar, tuvimos que sacarnos cada uno, el puñado de piojos y el huesito del hombro, tuvimos que echarlos a un tiesto. Allá en el volcán, hice mis saludos de presentación y cortesía al que era el padre de mi yerno: mi "compragente" (nguillanche)4. El era igual como gente. Así como éramos nosotros, así era esa gente del volcán", decía mi suegra que dijo su abuela.

"Y fue así como fui a entrevistarme para hacer la visita de cortesía de matrimonio.

-¡Cuánto has sufrido tú, ñaña, papay. Quería que nos viéramos, por eso hoy te fueron a buscar. Una de tus hijas, hija mía pasará a ser. Uno de mis hijos tiene tu hija para él, aunque siguen siendo tu hija y tu hijo, me dijo mi compragente". Así dijo la que fue mi abuela.

Así pasaron lunas. Un año, avanzando ya su curso. "Eso sí que no sé cuánto tiempo estuve en el volcán. No me dijo a mí cuánto tiempo.
Antes, no sabíamos medir cuanto tiempo pasaba, aunque sabíamos que cambiaba la luna y que el sol daba su vuelta. Ese año pues, el día señalado, me dijo mi "compragente".

-Vendrá hacia acá ese día tu marido. Tú tomarás un atajo para que te encuentres allí por donde pasará tu marido. En ese lugar deberás encender un fuego-. Así, tuve que dejar allá a mi hija. Me vinieron a dejar en donde estaba el cruce del camino donde debía esperar. Mi yerno, mi hija y los dos hijos que tenian, un hombre y una mujer, debían quedarse en el volcán. Ellos se volvían perros de día, por la noche mi hija y ellos volvían a ser gente". Así era esa gente del volcán, decía mi suegra que decía su abuelita.

"Después que hube tomado el atajo, no sé cuántos días estuve esperando. Un día sentí sonar la campanilla del caballo guía de una tropilla.

-¿Quién está junto a ese fuego?- dijo mi esposo, cuando llegó. Entonces escaparon mis hijos. Se espantaron al ver a su padre. Arrancaron montaña adentro. Cuando logré alcanzarlos y los cogí, estaban todos heridos y rasguñados por las ramas, al huir. Ya se habían vuelto salvajes mis hijos", decía la abuela de mi suegra.

"Cuando estuvimos en el volcán y entramos, salieron de allí unos chanchos que me atemorizaron. -Estos son cherrufe-, dijo mi compragente y ordenó que salieran. Después se acercaron unos perros con los ojos tapados por el pelo a olfatearnos, pero él dijo: -Estos de día no hacen nada-, decía la vieja abuela de mi suegra.

2.1 Clases de seres. Nos encontramos con la presencia de diversas clases de seres en el volcán. Por de pronto el dueño del volcán, su hijo y la gente que allí habita son de aspecto humano, sin embargo, tienen la propiedad de ser de aspecto humano por la noche y de aspecto animal por el día, perros. Además cuando traen el caballo a la madre de la niña que se desposa con uno de estos seres, no se ve a nadie, porque es de suponer, según la costumbre, que para esta ceremonia sea traído por algunos el animal, el cual la niña sacrificará y de la sangre que salte se hará una interpretación del futuro. Tampoco se ve nadie cuando van a dejar a la mujer al lugar de encuentro con su 
esposo. Por otra parte hay perros que no ven, "con los ojos tapados" dice literalmente el relato, los cuales son inofensivos de día. $Y$ existen también cerdos que son cherrufe, es decir elementos dominantemente destructores; se dice que bajan osando en la lava cuando hay erupciones s. Otros relatos informan sobre el cherrufe en forma de cometa, el cual se va al volcán (Cherrufe, José Huichaleo, Teodoro Schmidt, Imperial, IX Región), y sobre un zorro-brujo con cola semejante a un arcoiris que se transforma en fuego y también vuela hacia el volcán (relato del mismo narrador). Así, el volcán parece ser un centro de habitación que recoge y del que surgen seres diversos. En el relato Cagua-cagua, un ser que devora animales también es relacionado como procedente del volcán (en Kuramochi 1992 (1): 170. Relato de Alejandro Leninao Quidel, Camino a Curacautín).

De tal modo, según nuestra percepción, habría seres que pueden clasificarse en malignos y otros, protectores; tal es el caso de esta gente del volcán, Degünche, a pesar de que el relato no lo explicita, como protectores y originadores de riqueza, animales que le son dados a la madre (en los complementos etnográficos del relato), deben seguramente, pagársele tributo, de hecho una hija es entregada a esta gente.
Por otra parte, situados en la montaña, sabemos por otros relatos, los referidos a Kalfumalen, la doncella celestial, que ella es benigna aunque también puede tornarse destructiva por malas actuaciones del hombre, origina epidemias, vuelve loca a la gente. Don Mariano Cheuquefilo (Q. E. P. D, recién fallecido) se expresó de ella como wecufe. Ella adopta la forma de un cometa, se trata ahora de un cometa benéfico y no maligno como en el caso de cherrufe. También se nos narra que había en la montaña antes de Kalfumalen ancianos protectores: Piskulfe futa y Piskulfe kushe. Otro relato habla también de una anciana protectora de los viajeros, la cual protegía u originaba la destrucción en las aguas de quienes la trataban mal.

Frente a estos seres de la montaña están los seres de las aguas, -bajo forma de hombres, mujeres o animales- formas de shumpall que se encuentran en numerosos relatos: ngütran o visiones: perimontu. El más reciente que hemos recogido se trata de un potro que gira como remolino arrastrando y cobrando animales de los ganados que pasan y llevándoselos al agua: se trata de Tuay potro. Realmente quiere decir: al parecer de forma como de potro, así dice el relato, no usa directamente el término. Estos también pueden hacer bien, de hecho entregan pago cuando toman una mujer para
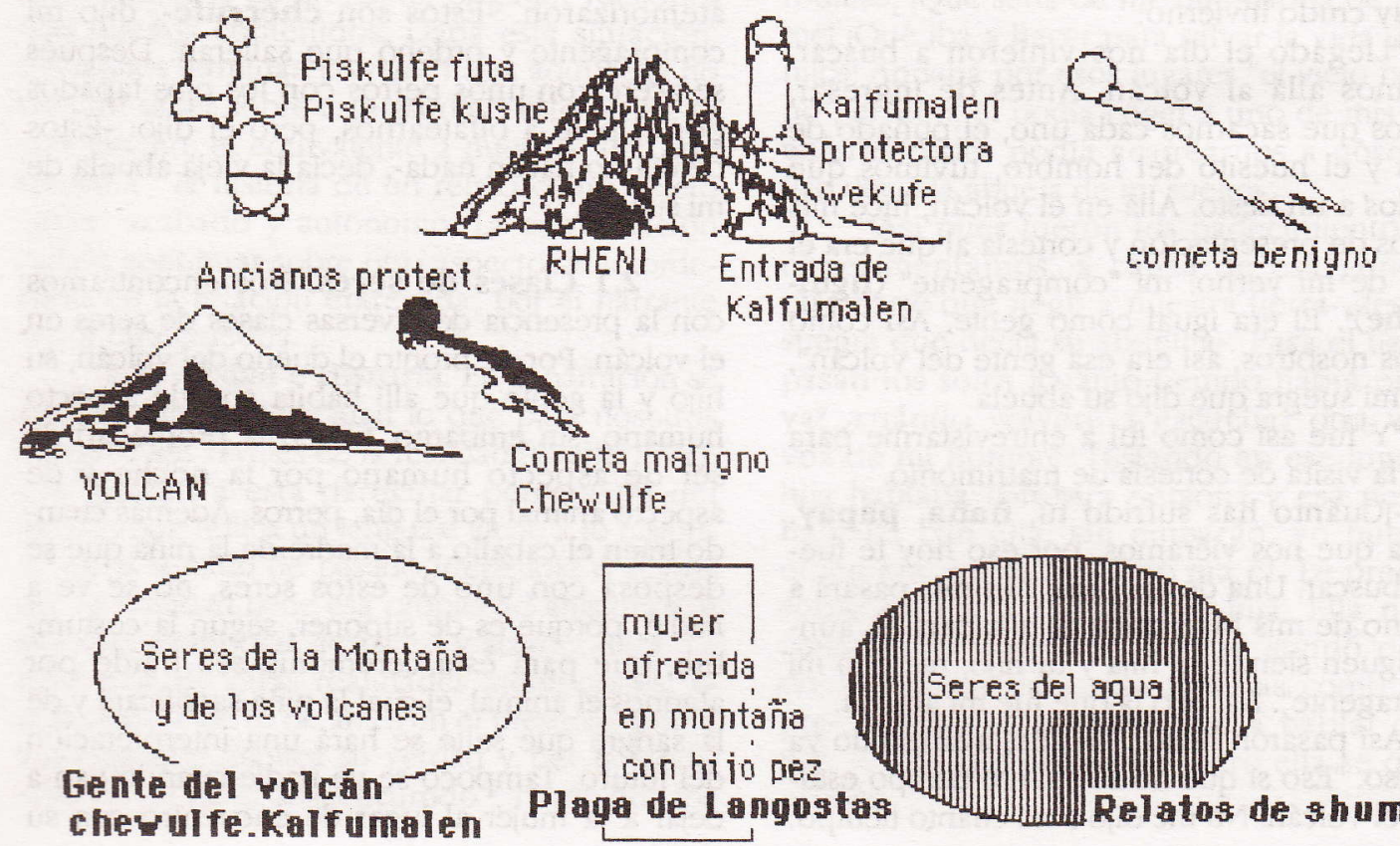

Plaga de Langostas 
desposarla, o dan agua, aunque cobran vida de animales, como narra "La laguna de Estanallín" (Loncoche).

Una forma mediacional entre los seres de la montaña y los seres del agua, parece encontrarse en el relato de perimontu "La plaga de langostas", de don Segundo Antimilla, Palguín, IX Región, en donde se ofrece una niña (paraguay se llama a estas jóvenes); ella es tomada por un ser de la montaña como esposa $y$ aparece trayendo un hijo que es un pez.

2.2 Ubicación externa-interna. Con respecto a la ubicación espacial de los seres de la montaña, éstos parecen ubicarse en su interior como es el caso de los degünche y otros habitantes se manifiestan en su exterior como cherrufe. También otros como el zorro cherrufe y cagua cagua son de actuación terrestre externa, aunque serían originarios del volcán.

En los seres de la montaña como Kalfumalen, se observa una cierta ubicuidad, pues tanto están en la montaña como fuera de ella en forma de cometa. Lo mismo ocurre con la forma de cometa del cherrufe y con su forma de serpiente de fuego. Algún relato como "Kuy mallen" de Sabina Melillan, Dolunco Bajo, Vilcún, la sitúan incluso en el agua. Esto es de la mayor relevancia por lo menos en dos aspectos del patrón congenitivo que subyace a estas concreciones o realidades percibidas:

1. Hay una atribución de carácter benigno y maligno, lo que tiene que ver con un aspecto sobrenatural ambiguamente ético;

2. Su pertenencia a espacios diversos, terrestre (interior de la montaña, atmosférico (el cielo), y acuático. Vienen a reforzar esta percepción ciertos seres mediacionales como la niña que aparece en el relato-perimontu: "Plaga de langostas", ya que ella ingresa a una montaña y es desposada por un ser del que le nace un hijo pez (supra): la polaridad montaña vs. agua, queda así anulada o conjugada. Por lo que, insistiría en que se trata de percepciones de categorías primarias, sin diferenciación ética clara ni topológica concreta ${ }^{6}$, y se relaciona con estadios de formalización abstractiva no realizados por la mente mapuche, lo cual tiene que ver también con el estatus de la oralidad.
Un caso semejante sucede con el lugar de los brujos: renhi. Este, por una interpretación de bajo la tierra, en el cual bajo adquiere la categoría de deíctico, para la cultura occidental significa subterráneo. Sin embargo en la cultura mapuche, puede tratarse de una caverna ¿está ésta bajo o sobre la tierra? la caverna por lo demás es un lugar de entrada de un ser benéfico como kalfumalen. Bajo la tierra que está bajo el agua se ubican también protectores como el toro de la laguna de Estanallín y también es rehni. Por ello es muy difícil situar en forma estratificada o polarizada los seres y atribuirles caracteres exclusivos en intentos de clasificación. Y así sucede también con la ubicación del mal, arriba, abajo, en la noche o en el día. Cierto es, a este respecto, que de la salida del sol al mediodía es un tiempo marcado benéficamente, pero el machi se enfrenta al mal tanto en la noche como en la mañana.

2.3 Relaciones parentales. Las relaciones parentales de casamiento se dan con ambos sexos: a) caso de mujer con gente masculina del volcán bueno, caso del relato que nos ocupa, y b) caso de unión de hombre con mujer del volcán, maligna pero protectora a la vez ("La hija del cherrufe", en Lenz 1896; figura 2). Además, en los Complementos del relato se habla de casamiento c) entre gentes del volcán: una hija del dueño del volcán viene a ser requerida en matrimonio, y le toca la consuegra -la abuela en el relato- hacer la conversación de cortesía, por encargo de su consuegro (el "compragente" de ella).

Lo mismo puede verse en las alianzas con los seres del agua: hay seres masculinos que desposan a niñas mapuches y seres femeninos que atraen a hombres mapuches.

En el caso de relaciones con seres antropomorfos, casan hombres con mujeres serpientes y mujeres serpientes tratan de casarse con hombres (ver Relatos en Kuramochi 1991).

Finalmente, los esposos malignos atraídos por los solteros que permanecen, antinaturalmente en este estado son: masculino: Punfuta y femenino: Punkure, formas de wecufe.

Con esto queremos señalar la doble dirección de las relaciones y la replicación de la unión natural que refrenda una cierta indiferenciación o continuidad de la realidad en la cual la mente mapuche se percibe comprendida. 


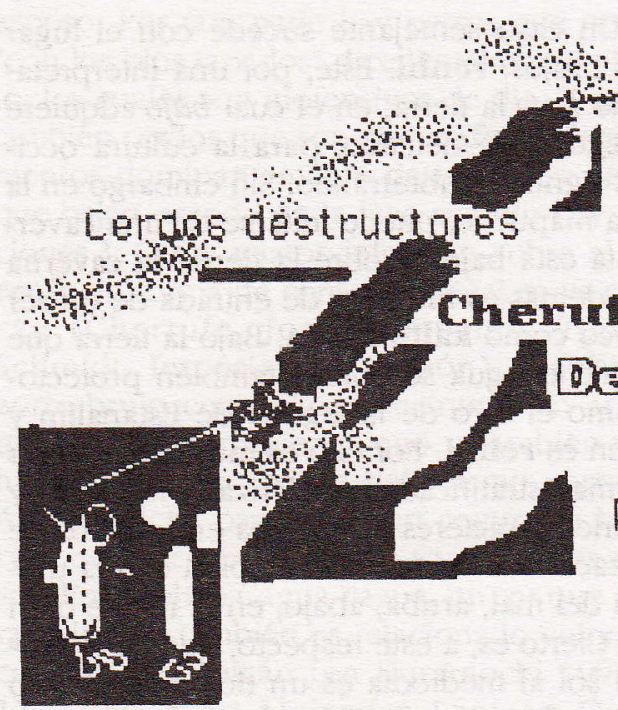

Mujer Cherufe + hombre

- La hija del Cherrure"

\section{Degunche + mujer Gente del Yoleán}

2.4 Bifuncionalidad de los agentes: Destrucción/Protección. Si morfológica y ónticamente los seres no naturales toman formas naturales, pudiendo situarse en lugares aparentemente opuestos - pensando con nuestros patrones ordenadores- como montaña y agua, tierra-cielo; alto-bajo; malo-bueno, éste y el otro, en cuanto agentes, son desencadenadores de acontecimientos benignos o destructivos según sea la naturaleza de la conducta humana; del mismo modo, su naturaleza transita bajo formas diversas pertenecientes a categorías distintas.

La oralidad a través de los relatos va estableciendo continuidades por bifuncionalismo, ambigüedad ontológica o mediaciones que tienden a reconstruir una cierta unidad originaria, dentro de la cual el hombre mapuche se percibe integrado o formando parte de ella. Así el mito vendría a ser un elemento de reconstitución de la unidad del mismo modo que el ritual atrae el pasado al presente creando una atemporalidad que lo liga a la eternidad en forma intermitente (véase Larraín 1988).

Las distribuciones forzadas por los filtros culturales del observador no mapuche pueden producir alteraciones serias a la concepción mapuche con lo que se retarda de paso una buena comunicación.

Así, la gente del volcán es "como gente", pero no es exactamente humana. Es benigna porque salva y da riqueza: animales a los padres de la niña desposada, pero esta protección o benefacción tiene su contrapartida, por de pronto la pérdida de la hija. El caudal profundo de la tradición oral nos permite leer hasta que no aparezca otra sección eslabón de este asunto- que esa riqueza fácil no es buena para el mapuche.

Las oraciones realizadas por la madre no sabemos a quién estaban dirigidas. Recordamos a este propósito, las oraciones hechas por Catriñir en el relato "Lago de sangre" ( en Kuramochi 1991); en él la persona ruega al dueño del agua y éste le da riquezas, pero luego la toma junto con la vida del beneficiado que de este modo pasa a ser víctima.

2.5 Estructuras simbólicas. El movimiento de conjunción con elementos o seres de naturaleza sobrenatural muestra la intención de unir lo natural humano con lo sobrenatural. Esta anexión se bifurca: 


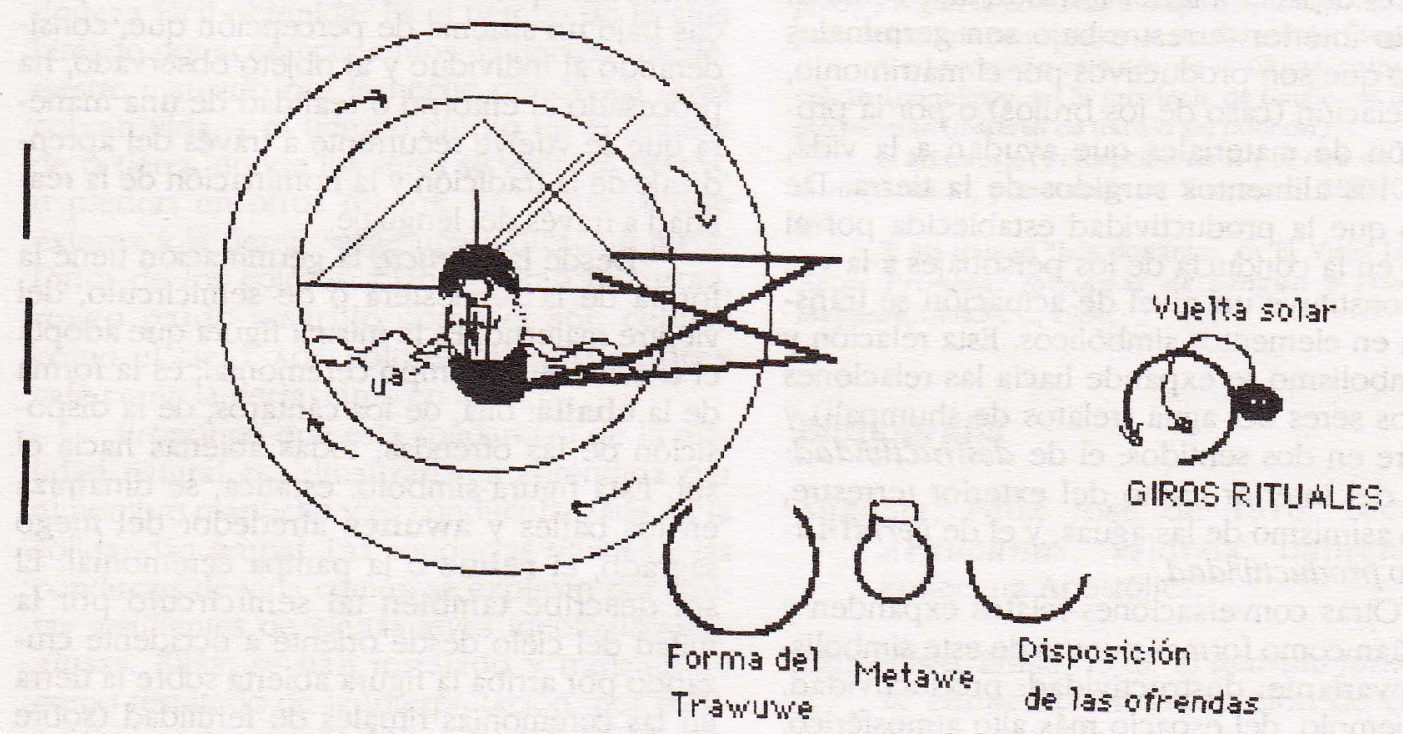

1. hacia lo interno, lo que está al interior de la montaña y del volcán: interior de la tierra alta; los seres del volcán y de la montaña son gente del volcán: degünche, animales -perros, cerdos- o el espíritu de una niña.

2. con lo exterior a ella; la comunicación se manifiesta con el exterior por los seres cometas o serpientes de fuego voladoras: Cherrufe (véase Sánchez 1990) o Kalfumalenes como cometas.

Los seres del volcán:degünche son gente de noche y perros de día, participan de características humanas y animales, y de seres sobrenaturales. Esta representación de la unión fecunda de lo humano con lo interno terrestre y lo externo atmosférico o sobrenatural, se ve reforzada en su simbolismo en el ritual por las palabras de la oración, los gritos de aliento, el humo y las rogaciones con humo de tabaco, todo dirigido a lo alto del cielo.

Por otra parte, lo terrestre alto encuentra su conjunción con lo acuático en la mediación de la niña paraguay que se une a un ser del agua en una montaña. Esto, que de alguna manera apunta a los orígenes acuáticos del hombre por el mito de los orígenes de tren y cai cai cuando las aguas luchan con la tierra, se expande en relaciones francas del hombre con seres del agua de naturaleza masculina y feme- nina. Y bajo la tierra, en lo subterrestre, se hallan seres con los que también el hombre interactúa. Por lo tanto lo externo y lo interno, lo de arriba en la montaña, en la atmósfera o en el cielo (destino de las oraciones), se ve en la interacción de hombres y mujeres que por el matrimonio unen estos espacios. Lo internoexterno es por lo demás análogo a la vida del hombre dentro y fuera de la madre. Asimismo lo subterrestre y lo alto son análogos a la vida del hombre terreno y su vida posterior a la muerte. La unión con lo terrestre interno, matriz germinal de la vida, se establece en los rituales de fertilidad echando muday a la tierra y gotas de la sangre de los animales sacrificados. También hay una ceremonia de enterrar los cántaros de muday; y en un hoyo se echan las partes internas, viscerales del animal en la rogación (Chosdoy, 1990). Estas son percepciones de la mente mapuche expresadas en estas estructuras simbólicas.

2.6 Simbólica topológica. Las interacciones manifiestas entre el hombre y el espacio terrestre alto: volcán-montaña, tanto exterior como interior, y entre el hombre y el espacio subterrestre: rehni y el espacio germinal interior de la tierra, encuentran su oposición y complementariedad con el espacio acuático. 
Tanto el espacio interior terrestre alto como el espacio interior terrestre bajo son germinales puesto que son productivos por el matrimonio, la asociación (caso de los brujos) o por la producción de materiales que ayudan a la vida, como los alimentos surgidos de la tierra. De modo que la productividad establecida por el relato en la conducta de los personajes a la vez que constituye un nivel de actuación se transforma en elementos simbólicos. Esta relación y su simbolismo se expande hacia las relaciones con los seres del agua (relatos de shumpall) y se abre en dos sentidos: el de destructividad: tanto del interior como del exterior terrestre, como asimismo de las aguas, y el de germinación o productividad.

Otras conversaciones-relatos expanden y se sitúan como formas nuevas de este simbolismo invariante: destructividad: productividad. Por ejemplo, del espacio más alto atmosférico, sobre el cherrufe destructor: como lava o como cometa, el fuego solar puede fecundar y así lo hace en una mujer (relato de Augusta); y puede dar vida por los elementos comestibles terrestres. Pero también puede destruir por la sequía. Asimismo las aguas de los relatos de inundaciones pueden ser benéficas para los habitantes, o pueden destruir como desmesurada presencia. Sin embargo, aquí hay otra intersección o mediación como el caso de la niña que en la montaña tiene un producto del agua ("La plaga de langostas", en Kuramochi 1991), porque el agua procede de la nieve derretida por la lava: fuego y agua. Las relaciones de este complejo sistema de dependencias y funciones opera en ambas direcciones desde el hombre a los objetos animados o sistemas organizados de materia como el sol y a la inversa.

La simbólica del relato se ve refrendada en el ritual en lo que se dirige hacia arriba, y en lo que se destina al interior de la tierra.

Siendo el relato un conocimiento verdadero que circula temporalizado sólo por los sujetos que lo asumen desde la voz narrativa, siendo además testimonial, opera en presente fusionándose con el ritual, ya que éste busca la inmanencia y el presente intemporal -uniendo pasado, presente y futuro- en la unión con la divinidad. Por tanto, las motivaciones y explicaciones de la conducta del pasado son una referencia para las conductas del presente.
Conductas aprendidas, no innatas sino adquiridas bajo un sistema de percepción que, considerando al individuo y al objeto observado, ha procesado el entorno o realidad de una manera que se vuelve recurrente a través del aprendizaje de la tradición y la nominación de la realidad a través del lenguaje.

Desde la icónica, la germinación tiene la forma de la semiesfera o de semicírculo, del vientre materno. Es la misma figura que adopta el trawuwe: el campo ceremonial; es la forma de la challa: olla, de los cántaros, de la disposición de las ofrendas, todas abiertas hacia el sol. Esta figura-símbolo: estática, se dinamiza en los bailes y awunes alrededor del fuego sagrado, el rehue o la pampa ceremonial. El sol describe también tal semicírculo por la mitad del cielo desde oriente a occidente cruzando por arriba la figura abierta sobre la tierra en las ceremonias rituales de fertilidad (sobre las dos semiesferas: celeste diurna y negra nocturna, hemos hablado a propósito del mito de Latrapai) ?

A pesar de la fuerte tentación de procesar dualísticamente esta simbólica, de acuerdo con nuestros sistemas ordenadores, me parece que se trata de un sistema de implicaciones múltiples y recíprocas. Sistema de referencias que como hemos apuntado, se explicita como tal en las determinaciones activas de los personajes relacionadores. Y como ellos están solidariamente relacionados con las personas, también determina la conducta de éstas en el presente.

2.7 Simbólica de los elementos. Los elementos aire, tierra, agua y fuego se encuentran aquí conjugados en sistemas solidarios, siendo ambivalentes y topológicamente no delimitados. Este sistema solidario se corresponde a nivel social con la solidaridad de la sociedad mapuche.

2.8 Simbólica temporal del relato. El relato del despojo se situa en el otoño, pues antes del invierno se encuentran con la gente del volcán; éstas lo llevan, para sortear el invierno, dentro del ámbito del volcán -terrestre alto-; allí hay productividad por el rito de casamiento y de nacimiento de hijos. Luego, "pasando bastante el año", dice el relato, salen -con riqueza de animales- del período invernal, por tanto, a la primavera. Queda en incógnita 
el verano, que podría ser de destrucción por la riqueza fácil obtenida. Es el tiempo de la vida hiteado por acontecimientos. El tiempo intraterrestre marcado por la noche donde los seres cobran vida, y el tiempo diurno en el interior de la tierra, donde los seres se vuelven perros, o piedras en otros relatos. En la luz celeste externa y la tierra, surge una indicación metafórica de los colores: blanco como la aurora, rojizo pardo-amarillo como el sol, celeste como el cielo, son colores buenos; pardo y café como la tierra, también lo son.

Propongo que esta solidaridad de la realidad natural espiritualizada es aprendida por el hombre mapuche y es conductualizada en la solidaridad grupal. Las conductas rituales y las conductas de vida común se explican por pautas resultantes de ciertas leyes ideológico-religiosas. Ellas, se han instalado y transmitido como resultado de la interpretación, por particulares percepciones de los mapas del mundo externo. Son resultado de un aprendizaje de la sociedad mapuche en el seno de la tradición. Proceso de organización al aprender a percibir por una experiencia constantemente vuelta a ser percepción y reedición cognitiva de los sucesos del mundo externo y los sucesos propioceptivos. Así se aprenden por el relato, el ritual, la conducta de los otros y, en general, la determinación cultural, los mapas del mundo externo que rigen la conducta que identifica a esta sociedad.

\section{Notas}

1. Al respecto se puede revisar mi trabajo "Comprendiendo una cultura a través de sus manifestaciones artísticas verbales: el caso mapuche", en Kuramochi 1992 (1): 189-202. Alli se puede ver la "realidad externa" del mapuche, su idea del bien y el mal, su relación con los semejantes, con los seres sobrenaturales, entre otras relaciones.

2. Uso este término en el sentido que propone Greimas en su Semántica estructural, Editorial Gredos, Madrid, 1971.

3. Así se observa con respecto a los llamados mitos diluviales de origen que incluyeron sacrificios humanos (Rosales 1969: 17-22); tal situación la observamos en muchos relatos, especialmente en la reedición del sacrificio debido al maremoto de 1961 (mi trabajo: "Contacto etnográfico con los sacrificios humanos en la cultura mapuche...", comunicación presentada al $47^{\circ}$ Congreso Internacional de Americanistas, New Orleans, E.E.U.U., julio de 1991. Además aparece editada en Kuramochi 1992 (2): 145-165).
4. Ngillanche: compra-gente, es el que había "comprado", según la costumbre mapuche, la hija de la mujer para desposarla con su hijo, un ser del volcán (degünche) 5.z La versión relatada de la última erupción del volcán Lonquimay, en la provincia de Cautín, es un ejemplo reciente (material de trabajo sin publicar)

6. Mi trabajo "Percepción de sí y el otro en la cultura mapuche...", presentado en Kuramochi 1992 (2): 167183.

7. Mi trabajo "Los donantes en El Viejo Latrapai", Actas Primeras Jornadas de Lengua y Literatura Mapucbe, UFRO-I.L., 1984.

\section{Bibliografia}

Augusta, Félix José de 1910. Lecturas Araucanas. Valdivia, Imprenta de Prefectura Apostólica.

Benveniste, Emile. 1970. El aparato formal de la enunciación. Traducción de circulación restringida.

Grebe, M. et al. 1972. "Cosmovisión mapuche", en: Cuadernos de la Realidad Nacional, 14. Santiago, Universidad Católica de Chile, Pp. 46-73.

Lenz, Rodolfo. 1896. Estudios Araucanos. Santiago, Imprenta Cervantes.

Kuramochi, Yosuke. 1991. Mitología mapuche. Quito, Ecuador, Editorial Abya Yala.

1992(1). Cultura Mapuche Vol. 1: Relaciones de rituales y tradiciones. Temuco, Ediciones de la Universidad Católica de Temuco.

1992 (2). Cultura Mapuche Vol.2: Relatos Mapuches. Temuco, Ediciones de la Universidad Católica de Temuco.

Larraín, Sara 1988. "El mito de Huitranalhue en la narrativa mapuche", en: Wenuleufu, camino del cielo. Santiago, Colección Aisthesis, Departamento de Estética, Facultad de Filosofia, Pontificia Universidad Católica de Chile, Ediciones Mar del Plata.

Rosales, Diego de Indiano. 1969. Historia General de el reino de Cbile, Flandes. Santiago, Editorial Universitaria. 


\section{ANEXO \\ Gente del Volcản}

\author{
Hortensia Lepín \\ Colimán, Perquenco
}

\section{Transcripción}

(1) küpay ngati pu malon, tati 'español', kom lefünkepi (2) nga pu che ñi ña nung em nga ñi eluetew (3) yean chi nga ñi kure pirkey ngati wentru, meli püñen nga (4) yerkey ngati kurewen. Doy amuchi, doy 'kore' chi komew (5) elan ngañi kure, pirkey ngati ngan kure, inche nga amuan (6) nga Argentina kudawmwli nga yerpatuaeymi pirkey nga (7) ñi kure, elkunonger purkey, chumtenmapuy chi nga kimlan nga (8) ñi chunteñmapun pin nga piken nga fill an tü nga ngillatuken (9) fillantü nga lukutuken fillantü nga ngümaken nga chumafun (10) chi chuchikünowafun chi nga montupeay may ñi püñen (11) müley nga 'leon' füta llamngen nga müñ malllleafenew nga (12) pikefuy nga ñi chuchuyem pikefuy ngañi nanüng femngechi nga (13) kutrankawyiñ ka tripanche nga ñi akunmew pikey ngañi chuchu (14) pikey nga ñi nanüng. Amulen nga rupay nga tripantu küyen (15) chuntepu chi nga allküñmayafiñ ngañi dungun ngañi wentru (16) ngütramkawkey ngañi püñen engu, welu kimlafiñ ngañi (17) chumngechi chi ngañi peyafiel pelafiñ nga, ramtufuiñ (18) nga ñi püñeñ dungulaenew, ayekünofemi, chem pipingetuy chi (19) chem mew kamta fente dungukeymi, ineg am ta dungupakeeymew, (20) pifiñ nga ramtufuiñ nga, welu nga chem pilaenew (21) rume nga fey ngaka putrün rupan antü rume fey nga (22) pewfal luwenew nga ti wentru, inche nga dunguñmapa (23) keeymi nga ni püñeñ, inche nga ñieñmayaeyu, fachantu (24) dunguafimi nga mi llalla pienew ngañi chaw feymeu (25) nga tüfa nga kimüwfalüwpapeyew, pienew ayiwün nga (26) feypietew, mülerkey nga che montukaperkelayan nga (27)fente nga fill antu nga weñangküleken nga tüfa nga (28) füt ay ngañi duam pikefuy nga ñi chuchu feymew (29) nga feypi ngañi nanüün fey nga ñi eleletew fey nga (30) petu ngütramkan. Amuley nga rupay feychi antu nga (31) elelpaeyew kiñe kulliñ pienew ngañi llallayeael, pen kiñe (32) antü, kiñe puliwen nga perumen nga kiñe kawell trapel (33) külerkey chem chi nga elpay nga, alün mew wefi ngañi (34) llalla ilolpaenew ngañi kulliñ ilotun nga (35) apeke lay entrin mew nga ñi meli pu püñeñ nga ñi ñiel (36) fey mew nga eluenew nga ñi kawell nga ilotuael fey mew nga (37) alün antu nga rulpaiñ nga iñ ilotun nga ngañi ñanüng nga (38)ñi chuchuyem pingañi ñanüng, feychi antu nga yewpayaiñ (39) weda tripantuay nga tüfa rume weda pukemay nga pirkey (40) nga pienew nga ñi llalla pikefuy... fey nga yengepaiñ (41) puiñ nga degüñ mew mülangey ngati 'puerta' konpuiñ (42) nga kiñeke rumantuñ mangeiñ nga... ñi... pütrar pi nga (43) femtukuñ mangen nga meñkuwe mew ka ñi püñeñ kom nga (44) ñi meli püñeñ nga femngen nga fey nga konpun nga chalipun (45) nga ñi ngillañchenke nga chumngechiley che nga (46) famngechi inchiñ in chumlen nga ka femngerkey nga (47) degüñ mew nga pikey nga ñi chuchuyem pikefuy ngañi (48) ñanüng femngechi nga pun pentukufiñ nga inche (49) nga ka pentukuenew: tunte weñangkülekey mi nga ñaña, (50) papay, fachantü nga pepaeyu, yefalmepeyu ngati, (51) yengemeymi nga, welu kiñe nga mi püñeñ inche ngañi ñawe (52) ngetuay, inche nga ñi fotüm nga dew nga ñieñmaeymew (53) pienew nga ñi ngillanche pienew nga chuchu yem (54) femnge chi nga rulpaiñ tripantu amuley nga tripantu ñi (55) rupan, fachantü ka elayiñ nga dungu ngillatuiñ (56) nga pinga tunten tripantu dewma rupay ngillatun nga (57) müley kom kellupun chumngechi nga kellukey nga che (58) fempun nga pikefuy ñi chuchuyem pikefuy nga ñi nanäüng, (59) welu chunten mapunchi kimplan fanten mapun pilaenew (60) kuyfi am kimkenofulu inchiñ tunte rupan antü küyen (61) tripantu tuntepun chi feychi antü küpatuay tami (62) füta pienew añi ngillanche katrü rüpüleputuaymi (63) chew ngañi rupapayal ngami füta feymew nga üyüm (64) kütralküleputuay papay pienew ngañi ngillanche (65) femngechi nga elmen ngañi püñeñ elngepatun nga chew (66) ngañi katrir üpülepatual nga femngechi nga elpatuenew (67) nga ñi llalla epu püñeñ nga ñiey ngañi püñeñ eñmen nga (68) kiñe püñeñ kiñe domo püñeñ antu ngatrewa ngetuy nga (69) ñi püñeñ pun nga chengetuy nga ñi püneñ, femngerkey (70) nga feychi 
che nga degünche pikefuy ngañi nanüngem (71) nga ñi chuchuyem pi nga ñi nañüng femngechi wiñon (72) müfü antüpatun chi may ka feychi katrür üpülepatun fey nga (73) tralewürkey ngañi 'kampana' küpaley ngañi 'tropilla' kawell (74) enüy am ta müley kütral ta müley pipay nga. Lefmawingañi (75) pu püñeñ atawi nga ñi pupüñeñ pelu ngañi chaw, kom lefkoni nga (76) pu mawida re ngallu nga nütufiñ nga femngechi nga, kom nga (77) wichafi nga dewma awkawi nga ñi püñeñ pikey ngañi chuchuyem (78) pikefuy ngañi ñanüng em.

\section{Traducción}

(1) Vino los guerra (asalto) los españoles todo correr (abandonar) el lugar (2) era los gente mi suegra era su medio (3) llevar será era mi señora dijo el hombre, cuatro hijo era (4) lleva el matrimonio. Más va más corre el agua en (5) dejar (yo) era mi mujer, dijo el dueño mujer, yo era ir yo (6) era Argentina trabajar yo allá y volver era pasar a llevarte yo a ti díjole era (7) su mujer, paso a dejar cuando iba. Cuánto tiempo allá era saber yo no (8)cuánto allá dijo era decía era todo día era orar yo (9) todo día era rodillas yo todo día era llevar yo era que hacer yo (10) cual ser para yo era salvar será es mi hijo (11) hay era león viejo hermana era tomármelo era (12) decía era abuela decía mi suegra así era (13) sufrimiento otro salir gente (otra raza) era llegó (por) dice mi abuelo (14) cuánto tiempo era escuchar yo su hablar (voz) mi hombre (16) conversar con su hijo(a) ellos dos pero saber no yo su (17) como era ver a él ver yo no era, pregunté (18) era mi hijo(a) hablar no a mí, rió (sonrió) no más, que diciendo otra vez es (19) por qué es tanto hablar tú quién es hablar viene a ti, (20) dijo era pregunté era, pero era que dijo nada (21) mucho era es era y mientras pasan día mucho es era (22) ver dar a mí era el hombre, yo era hablar venir (23)a tú era tú hija(o) yo era tenértelo, hoy (24) hablar tú era tu suegra dijome era mi padre por eso (25) era éste era saber dar a ti díjome alegrarme era (26) decir eso, hay pues era gente salvar tal vez yo era (27) tanto era todo día era pena tener yo era éste era (28) grande ser mi pensamiento decía era mi abuela entonces (29) era dijo era mi suegra es era mi darme es era (30) estoy conversar va era pasa ese día era (31) dejar vino un animal dijo me era mi yerno será, vi un (32) caballo atado estar (33) que era dejar vino era, harto en aparecía mi (34) yerno carne hacer vino su animal carne comer era (35) casi morir inanición en era cuatro los hijo(a) era mi tener (36) entonces era dio a mí era su caballo era carne para mi entonces era (37) harto día era pasamos era nuestro comer era era mi suegra era (38) mi abuela dijo mi suegra. Ese día era llevarlo a ustedes (39) mal año será era éste mucho mal invierno será era dijo (40) era dijo a mí era mi yerno dijo que entonces llevar ser nosotros (41) llegamos allá era volcán en abierto fue el puerta entramos nosotros (42) era uno de puñados nosotros era mi piojo dijo era (43) así uno de nosotros era tiesto en y mi hijo todos era (44) mis cuatro hijo(a) era esa hacer era entonces entramos era saludé allá (45) era mi compra gente ser era como así estar gente era (46) así nosotros como ser era y ser así era (47) volcán en era dice era mi abuela decía era mi (48) suegra así era llegué entrevista yo (49) era y entrevista: cuanto pena tener tu era ñaña $(50)$ papay, hoy era verte manda a buscar era (51) llevar para acá a ti era, pero una era tu hijo(a) y era mi hija (52) será, yo era mi hijo era ya era tenértelo (53) díjome era mi compra gente dijome era mi abuelo que fue (54) así era pasamos años va era año (55) pasan este dia y dejaremos era sunto rogamos (56) era dijo cuanto año ya pasó rogar era (57) hay todo ayuda allá como así era ayuda era gente (58) así hice allá era decía mi abuela decía era mi suegra (59) pero cuánto tiempo yo allá saber no tanto tiempo allá decir no a mí (60) antes saber no nosotros cuánto pasar sol luna (61) año cuánto allá ese día venir acá tu (62) marido dijo a mí compra gente corta camino estar allá tú (63) donde era su pasar tu marido ahí era prender (64) fuego estar allí tu papay dijo a mí compra gente (65) asi era dejar allá mi hijo(a) dejarme acá era donde (66) corta camino estar yo era así era dejarme acá (67) mi yerno dos hijo era tiene mi hija deja allá era (68) un hijo(a) un mujer hijo(a) día era perro ser es era (69) mi hijo(a) noche era gente ser es era mi hijo es ser es (70) era esa gente era volcán gente decía mi suegra (71) era mi abuela dijo mi suegra así (72) cuanto días acá será sí y esa vez atajo camino está es era (73) 
sonó su campana venía su tropilla caballo (74) quien esta fuego dijo acá era corriéronse mi (75) hijo(a) espanto mi hijo ver su papá todo arrancaron (76) montaña apenas tomé de nuevo era así era todo (77) rasguños ya joven era hijo dice mi abuela (78) decía mi suegra.

\section{Versión semiespañolizada}

(1) Cuando llegó a nuestro lugar la guerra contra los españoles, todos huyeron dejando las tierras. (2) La historia de este asalto es en la tierra de la familia de mi suegra; me la dejó ella a través de su conversación. (3)"Llevaré a mi esposa" dijo el hombre, tenían cuatro hijos (4) y con ellos partió el matrimonio. Donde el río es más correntoso, (5) allí dejaré a mi mujer. Dijo el esposo: -yo voy a irme (6) a trabajar a Argentina; cuando vuelva, pasaré a buscarte. Así le dijo a la que era (7) su esposa, Así, partieron y pasó a dejarla junto a ese lugar del río. "El tiempo que él estaría por allá (8) yo no lo sabía", dijo la mujer. Todo el día me lo pasaba haciendo rogaciones. (9)Todo el día estaba de rodillas, ¡Qué sería de mí, qué habría de pasarme! (10);Qué iba a hacer para salvar la vida de mis hijos! (11) Andaba por ahí "el viejo hermano", el león, él podía coger a uno de mis hijos. (12) Eso decía la abuela de mi suegra. Así eran (13) los padecimientos que experimentaba, esto a causa de gente distinta que llegó a nuestra tierra, decía mi suegra que decía su abuelita. (14) ¿Cuánto tiempo pasará cuando vuelva a escuchar la voz de mi hombre? (16) Mi hija hablaba con otra persona, sin embargo, yo no sabía (17) cómo era él, nunca lo vi. Le pregunté (18) la que era mi hija. No me contestó, sólo se sonrió diciendo (19) "qué es lo que andas hablando otra vez". -¿Quién es el que viene a hablar contigo?- (20) volví a preguntar. Pero ella no dijo nada.

(21) Pasaron muchos días. Después de transcurrido mucho tiempo, (22) se presentó ante mí el que hablaba con mi hija (23) y me dijo: -Yo era el que venía a hablar con tu hija. Yo te la tengo. "Hoy (24) vas a ir a hablar con tu suegra" -me dijo mi padre, por eso (25) vine a darme a conocer y a conocerte-. Me alegré de que (26) dijera esto. Había pues gente que pudiera salvarnos. (27) Todo el tiempo estaba yo tan apenada y la (28) preocupación mía era tan grande - decía mi abuela. Entonces (29) así era- dijo la que era mi suegra. El nos daría (30) con qué alimentarnos, dijo en su conversación ese día el visitante, antes de irse. Así, después, al otro día, (31) vino a traer un animal el que sería mi yerno. Vi al animal (32) parado donde lo vino a dejar. Mi yerno apareció tras el animal (34) y vino a carnearlo. Comimos la carne del animal. (35) Ya casi moríamos de inanición yo y mis cuatro hijos. Entonces (36) me entregó el caballo, era para mí. (37)Hartos día tuvimos para comer. Mi suegra decía lo que decía su abuelita del hombre ese. (38) Otro día los llevaré a todos ustedes, (39) porque éste va ser una año muy malo, muy crudo-, (40) dijo el que era mi yerno. Entonces nos vinieron a buscar. (41) Llegamos allá al volcán, una "puerta" abrió y entramos; (42) pero antes de ingresar, tuvimos que sacarnos, puñados de piojos (43) y tuvimos que echarlos a un tiesto. (44) Mis hijos tuvieron que hacer lo mismo. Entonces entramos. Allá en el volcán, hice mis saludos (45) al que era el padre de mi yerno: mi compragente. (46) El era igual como gente. Así como éramos nosotros, así era (47) esa gente del volcán, decía mi suegra que decía (48) la abuela. Y era así como llegué a entrevistarme, (49) a la visita de cortesía de matrimonio. ¡Cuánto has sufrido tú, ñaña, (50) papay!. Hoy quería que nos viéramos, por eso te mandé a buscar. (51) Pero una de tus hijas, hija mía pasará a ser. (52) Uno de mis hijos tiene tu hija para él, aunque siguen siendo tu hija y tu hijo, (53) dijo mi compragente. Así dijo la que fue mi abuela.

(54) Así pasaron los años. (55) Pasaron. Un día dijo el "compra-gente": Vamos a iniciar "algo", vamos a empezar a rogar. (56)Cuántos pasarían desde que se hizo ese ngillatum. (57) Hubo ngillatun, yo ayudé como ayuda la gente (58) en todo. En todo, decía mi abuela, decía mi suegra. (59) Pero cuánto tiempo estuve en el volcán, no lo sé. (60) Antes no sabíamos nosotros cuánto tiempo pasaba. (61) Ese día se vendrá tu marido(62) me dijo mi compra-gente. Tú estarás en el atajo del camino, (63) allí donde pasará tu marido, allí (64) prenderás fuego tú, señora me dijo. (65) Así fui a dejar a mi hija. Vinieron a dejarme donde (66) estaba el atajo del camino. Vino a dejarme mi yerno. (67) Dos hijos tuvo la hija que fui a dejar. (68) Fui 
a dejar una hija mujer; de día pasaba a ser perro mi hija. (69) De noche se volvía gente mi hija. Así es (70) la gente en el volcán, (71) es que decía mi abuela, decía mi suegra. Así volví. (72) Cuántos días estaría yo aquí. Y esa vez estaba yo en el atajo del camino. (73) Tantineó una campana (de caballo), venía su tropilla de caballos (de su esposo). (74) ¿Quién está allí, ya que hay fuego?- vino a decir. (75) Se arrancaron mis hijos, se espantaron al ver a su padre. Se metieron corriendo (76) a la montaña. Apenas los tomé de nuevo (los traje). (77) Todos rasguñados; estaban alzados (amontañados) mis hijos, decía mi abuela, (78) decía mi suegra.

\section{Versión Española}

A causa de uno de los tantos asaltos españoles, la gente tuvo que abandonar sus tierras en el lugar en que vivía la abuelita de mi suegra. Esta conversación que estoy dando a mi sobrina me la entregó mi suegra. Era así:

Será mejor llevar a mi señora y a mis cuatro hijos de aquí, se dijo el hombre. De este modo, el matrimonio con sus cuatro hijos emprendió el camino hacia la cordillera. El hombre conocía un lugar donde bajaba el agua con gran turbulencia y pensaba dejar allí a su mujer y a sus hijos. El pasaría al otro lado de la cordillera.

- Voy a ir a Argentina a trabajar, luego volveré para pasarte a buscar- le dijo a su mujer. Llegados al lugar, la dejó allí su esposo.

No sabía cuánto tiempo él estaría por allí, decía la abuela de mi suegra.

"Todos los días oraba yo; todos los días me arrodillaba para pedir por nuestra vida. Lloraba todos los días y pensaba qué iría a ser de mí, qué podía hacer en esa situación. ¿Se irían a salvar mis hijos? Anda por aquí el viejo hermano, el león y quién sabe si podría coger a alguno de mis hijos", decía mi suegra que decía su abuela.

-Así era nuestro sufrimiento y aflicción a causa de esta gente venida de otros lugares, decía la abuela de mi suegra.

Pasó así el tiempo, -sola con mis hijos-, quizás cuántos años, cuántas lunas pasaron, cuánto tiempo; ¿volvería yo a oír la voz de mi hombre?
Comencé a escuchar conversaciones de mi hija con alguien. Traté de ver con quién hablaba, y al preguntarle, no me contestó nada, se limitó a sonreírse. -Ya andas hablando tonteras -me dijo. ¿Con quién conversas tanto?insistí, pero ella no me informó nada.

Mientras, siguieron pasando los días. Entonces un día se hizo visible para mí el hombre que conversaba con mi hija. -Yo era el que venía a hablar con tu hija. Será ahora de ambos, porque yo voy a tenerla ahora. Después dijo: -Mi padre me ha dicho que me presentara y conversara contigo, por eso me doy a conocer a ti.

Yo me alegré al escuchar sus palabras, eso significa que había gente en ese lugar y que podríamos salvarnos por ellos. Y también habíamos pasado tantos días llenos de pena, pero ahora surgía la esperanza. Esto decía la abuela de mi suegra, ésta me dejó a mí este conocimiento que ahora te traspaso en esta conversación. El hombre antes de irse me dijo: -Pasado este día, volveré a dejarte un animal para que te alimentes-. Dicho esto, se fue el que iba a ser mi yerno.

Al llegar el día, de mañana, apareció un caballo atado. No se veía a nadie que lo hubiera traído. ¿Quién lo habría venido a dejar?, pensé. Poco después apareció mi yerno. Era la entrega real de lo ofrecido; él vino a sacrificarlo y a faenar para mí el animal. Así, después de haber estado a punto de morir de hambre con mis cuatro hijos, pudimos comer carne. Entonces mi yerno me entregó formalmente la carne de su animal. Varios días pasamos comiendo del animal, decía la abuela de mi suegra.

Después me dijo mi yerno: -Este será un mal año, el invierno será muy crudo, por lo que te llevaremos de aquí.

Vinieron pues a buscarnos y llegamos al volcán. Nos fue abierta la "puerta" y entramos. Antes de llegar nos sacaron a mí y a mis hijos, en puñados, los piojos y los echaron a un gran tiesto que ahí había; lo mismo hicieron con nuestro huesito del hombro, lo sacaron y echaron también al tiesto, para que pudiéramos entrar.

Entré entonces e hice mis saludos a la gente que había "comprado" a mi hija. Igual como somos nosotros es la gente del volcán, decía mi suegra que decía su abuela. 
Una vez allá cumplimos con la ceremonia de presentaciones, saludos y formalización del matrimonio. El padre de mi yerno me dijo en su conversación: -Cuánta pena has tenido por tanto tiempo, ñaña. Pero hoy nos hemos encontrado. He mandado a buscarte hoy. Una de tus hijas pasará a ser mi hija, ya que uno de mis hijos la ha tomado para él-. Así habló el que tomaba mi hija para su hijo.

Un día, alguien dijo a mi consuegro que iba a hacer una ceremonia de ruego. ¿Cuánto tiempo hará de que se hizo esa ceremonia? Se hizo pues la ceremonia y yo participé ayudando como debe hacerse en estos casos. No sé cuánto tiempo estuve allá, decía la abuela de mi suegra. Antes no sabíamos medir el tiempo sino en soles y lunas.

Al tiempo, me dijo mi consuegro: -Deberías ir desde aquí al lugar donde el camino tiene un atajo, porque por allí pasará tu marido que viene de regreso. Tendrás que hacer allí una fogata para esperarlo.

Así pues, fue como fui a dejar a mi hija al volcán. Ella tuvo dos hijos de mi yerno. Durante el día ella se convertía en perro y en la noche volvía a tener su forma humana; igual sucedía con toda esa gente del volcán, así son ellos. La gente del volcán vino a dejarme a este atajo del camino. Ahí me puse a esperar. No sé cuánto tiempo estuve esperando. Sentí de pronto tintinar la campanilla de un caballo. Era mi esposo que venía con una tropilla de caballos.

-¿Quén está ahí en esa fogata? -dijo al acercarse. Entonces, al verlo, mis hijos escaparon despavoridos metiéndose montaña adentro; salí en su persecución y los traje de vuelta. Venían llenos de rasguños que se hicieron en la huida. Salvajes se habían vuelto mis hijos. Así decía mi abuela, decía mi suegra. 